\title{
Academic Librarian Research: An Update to a Survey of Attitudes, Involvement, and Perceived Capabilities
}

\author{
Marie R. Kennedy and Kristine R. Brancolini
}

\begin{abstract}
This article reports the results of a 2015 survey that updates and extends the authors' 2010 survey of academic librarians, to learn of the current state of their attitudes, involvement, and perceived capabilities in the research process. A key change in the 2015 survey is the use of an expanded research confidence scale, designed by the authors. They also added questions on research training and institutional support for research. The results of this survey add to the growing body of research examining the success factors for librarian-researchers. Research selfefficacy continues to be a predictor of research success. Institutional support for research, including both formal and informal mentorship, is increasing and associated with research success.
\end{abstract}

\section{Introduction}

For decades now librarians have been conducting research and disseminating the results of their research. Academic librarians have produced most of this research, primarily due to the impact of faculty status for many academic librarians and the influence of research practice among the teaching faculty. In the early 2000s, the profession began to focus on evidence-based practice, assessment, and accountability, leading more librarians to think about how research might enhance their performance as librarians-bridging the gap between research and practice. However, there has been a nagging fear that research conducted by librarians does not meet recognized standards for reliability and validity and that "publish or perish" has had a negative impact on the quality of librarian research.

In 2010, the authors began thinking about ways to increase the number of librarians who conduct and disseminate research that meets the highest standards for rigor. Inspired by NSF-funded research training for anthropologists, the authors thought novice librarian-researchers might benefit from a similar program, consisting of both providing instruction in social science research methods and assembling a group of like-minded librarians who would support one another's research efforts. The authors read widely

Marie R. Kennedy is Serials E Electronic Resources Librarian and Kristine R. Brancolini is Dean of the Library, both at Loyola Marymount University; e-mail:marie.kennedy@lmu.edu, brancoli@lmu.edu. (C2018 Marie R. Kennedy and Kristine R. Brancolini, Attribution-NonCommercial (http://creativecommons.org/ licenses/by-nc/4.0/) CC BY-NC. 
in the literature on the topic of librarian-researchers and conducted a national survey of academic librarians to describe the current state of academic librarians conducting social science research. The results regarding both barriers to research and supports for research were used to develop a research-focused continuing education program for academic librarians. Based on survey instruments developed by Powell, Baker, and Mika $^{1}$ and Henry and Neville, ${ }^{2}$ the authors' December 2010 survey focused on current research practice, confidence in completing the steps of a research project, methods training experiences, and institutional support for conducting research. ${ }^{3}$

Informed by the historical literature and the results of their survey of current academic librarians, the authors developed a research-focused continuing education program for academic librarians, the Institute for Research Design in Librarianship (IRDL). IRDL is designed to overcome some of the identified barriers to librarian research productivity and to increase the ability of librarians to conduct reliable and valid research. In 2013, the authors received funding for IRDL from the Institute of Museum and Library Services to support three cohorts of approximately 20 novice librarianresearchers in completing research methods training and a year-long research project of their own design. The program addresses many of the research barriers identified by academic librarians, including lack of research skills, lack of research confidence, lack of time, lack of a research community, and lack of institutional support-with an emphasis on providing librarians with appropriate training in research methods, which builds research confidence, and with time to focus attention on a single research project within a supportive environment.

In 2015, the authors conducted a new survey to gauge any changes that may have occurred since their 2010 survey and to discern research success factors among academic librarian-researchers. The 2015 survey expanded upon the 2010 instrument, including additional questions based upon recent findings regarding librarian-researchers, as well as the authors' experience with the 2013 and 2014 IRDL cohorts. This article reports the findings of the 2015 survey; and, to provide a longitudinal perspective, the authors also compare the responses from their 2010 survey and the study by Powell, Baker, and Mika, which addressed many of the same issues. ${ }^{4}$

The authors find the following definition of research to be useful when discussing the breadth of the types of research in which academic librarians participate:

"The process of arriving at dependable solutions to problems/questions/hypotheses through the planned and systematic collection, analysis, and interpretation of data: it may be applied or theoretical in nature and use quantitative or qualitative methods. (This definition does not include library research that is limited to activities such as compiling bibliographies and searching catalogs)."

This definition was used as a guide for respondents to both the 2010 and 2015 surveys.

\section{Literature Review}

An examination of the literature indicates that academic librarians are actively conducting research that supports decision making at their libraries, evaluates the operation of libraries, contributes to theoretical underpinnings of librarianship, and advances the field of information and library science. Librarians are motivated to conduct research by both extrinsic and intrinsic factors. The most common extrinsic factors are the requirements of promotion and tenure and annual merit pay increases, but many researchers also note the strength of intrinsic factors such as personal satisfaction, intellectual curiosity, and the desire to contribute to their profession. ${ }^{6}$ The concept of a practitioner-researcher is widely accepted in fields such as healthcare, education, and 
social work, but this description was not applied to librarians until 2000. ${ }^{7}$ Watson-Boone connected the work of Peter Jarvis, author of The Practitioner-Researcher: Developing Theory from Practice, with the research published by academic librarians. ${ }^{8}$ Jarvis studied professionals as problem solvers and continuous learners. ${ }^{9}$ Watson-Boone examined 24 articles in The Journal of Academic Librarianship through the lens of practitioner-researchers and concluded that the authors of these articles "illustrate the ability to problematize and study issues related to everyday academic library practice; subsequent publishing then advances knowledge of librarianship. The authors' efforts improve their own practice and further develop their own levels of expertise." ${ }^{10}$ This approach to librarian research has led to a new appreciation for the benefits that conducting and disseminating research accrue to the individual, to the institution, and to the profession.

An analysis of the authorship of library and information science (LIS) research articles found that librarian-researchers are active contributors of research to the profession's most important peer-reviewed journals. ${ }^{11}$ Academic librarians author the majority of articles published in LIS journals, ${ }^{12}$ including the profession's most highly regarded peer-reviewed journals. ${ }^{13}$ Galbraith et al. studied the authorship of articles published in the top 23 high-impact LIS journals in 2007 and 2009. They found that 42 percent of the articles were written by academic librarians and 19 percent by LIS professors. ${ }^{14}$ Of the librarian authors, 65 percent worked at libraries with faculty status and tenure. The study's authors also found that faculty status - with its attendant need to "publish or perish" - does not contribute to the publication of many low-quality articles. Rather, "faculty status may actually encourage publication in the most respected journals." 15 The criteria for tenure and promotion have intensified during the past two decades, and the research output of academic librarians reflects these changes.

Researchers have studied the obstacles that librarians confront in the conduct of research. Some of the obstacles to conducting research are reported as lack of time to complete a research project, unfamiliarity with the research process, lack of support for research (both emotional and monetary), lack of research confidence, discouraging jargon, inadequate education in research methods, and lack of motivation. ${ }^{16}$ Many librarians report that they received little or no training in research methods as part of their LIS master's degree. However, Luo found no statistically significant relationship between taking a research methods course and a librarian's research involvement. ${ }^{17}$ This finding is consistent with Powell, Baker, and Mika ${ }^{18}$ and Kennedy and Brancolini; ${ }^{19}$ neither study found a statistically significant relationship between conducting research and the respondents' belief that the LIS master's degree prepared them to conduct research. Librarians have found other ways to fill gaps in their research methods education, most notably self-education activities (such as professional reading and online tutorials) and continuing education programs (such as courses, workshops, and conference programs).

As the barriers and challenges to librarian research success are now better understood, researchers may turn their attention to the factors that enable research success. Researchers have recently focused on institutional and administrative support. ${ }^{20}$ These studies address the possibility of shifting organizational culture to be more aware and more supportive of research in academic libraries, which will ultimately help address the "lack of time" and "lack of support" barriers to librarian research. In something of a paradigm shift, many researchers have changed their language from the negative-how to overcome barriers - to the positive-identifying factors that lead to the successful completion and dissemination of research. Hoffman, Berg, and Koufogiannakis conducted a comprehensive literature review of empirical studies focused on research success factors, both in librarianship and in other fields. ${ }^{21}$ They found that research success requires many interrelated conditions. They grouped 16 factors into three 
categories: "individual attributes, peers and community, and institutional structures and supports," 22 with many factors occurring in more than one category. Hoffman, Berg, and Koufogiannakis found that research mentoring is a well-recognized success factor for practitioner-researchers in fields such as medicine. Mentoring is a common practice in academic libraries, but its effectiveness as a research success factor has not been studied extensively in librarianship. Most research has focused on early career researchers, but Hollister recently studied posttenure and continuing-appointment librarians. ${ }^{23}$ Hollister found that librarians who described their library atmosphere as nurturing, encouraging, or supportive of scholarship were significantly more likely to be producing research than those who reported library cultures and structures that were described with words like demoralizing, exhausting, unsupportive, and hostile. ${ }^{24}$

The authors' 2010 survey examined both research barriers and success factors, but with the development of IRDL, they have turned their attention to providing deeper insight into success factors that have been identified in recent articles. The authors added questions to the 2015 survey to more fully explore three factors: the impact of research self-efficacy (research confidence); educational experiences - the completion of a master's thesis and statistics courses; and formal and informal research mentoring and other forms of institutional support. Here is the rationale for expanding the survey on those three factors.

Research Self-efficacy (Q10-17). Research self-efficacy has been found to be a predictor of research success among practitioner-researchers in a variety of disciplines, including psychologists, ${ }^{25}$ psychotherapists, ${ }^{26}$ and physicians.$^{27}$ People with a high degree of research self-efficacy have confidence in their ability to perform successfully the tasks associated with conducting research. ${ }^{28}$ Like academic librarians, some members of these practitioner-researcher communities report that they struggle with the demands of job performance and conducting research. To measure research self-efficacy among academic librarians, the authors developed a 10-item research self-confidence scale, the Librarian Research Confidence Scale (LRCS) for use in the 2010 survey. Research confidence was found to be a statistically significant predictor of research success among academic librarians. ${ }^{29}$

Researchers studying other communities of practitioner-researchers found that research self-efficacy can be increased through instruction and encouragement. Holden et al. measured research self-efficacy to assess learning in a research training environment, a social work graduate program. ${ }^{30}$ They created a research self-efficacy scale appropriate to social work education to use as "an outcome measure for a series of evaluations of social work research education," ${ }^{31}$ which consists of a two-semester research sequence required by the Council on Social Work Education (CSWE). Holden et al. found statistically significant increases in research self-efficacy over one semester's instruction, both for participants and for each question. To measure the effects of the IRDL summer research workshop on research self-efficacy and to focus the workshop curriculum on areas of low self-efficacy, the authors revised their 10-item LRCS to create an expanded, 38-item research self-efficacy scale, LRCS-38. The authors used LRCS-38 with three cohorts of IRDL Scholars. However, the authors had not tested this scale with a large sample of librarians, which is required for factor analysis. The authors included the LRCS-38 as part of the 2015 survey and have since performed a factor analysis on those results, which will be reported in a future article.

Master's thesis ( $Q 21-Q 22)$ and statistics courses (Q22-Q23). All academic librarians possess a master's degree-or perhaps two, typically a MLIS and a subject master's - but not a PhD. The 2010 survey found that only 26 percent of respondents felt that their LIS master's program prepared them to conduct research, but what elements in a LIS master's program might contribute to research success? ${ }^{32}$ Sassen and Wahl observed, 
"An academic librarian who has not written a thesis or dissertation almost certainly has a less rigorous educational background in research methods than the typical teaching faculty member." ${ }^{\prime 33}$ Researchers in psychology education have studied the graduate research training environment and found that one research success factor after graduate school is the early, "minimally threatening" introduction to research: "It is important to involve graduate students in scientific work from very early on in their training, and at a level that is appropriate to their understanding of research." ${ }^{34}$ In talking informally with proficient librarian-researchers, many noted that they developed an interest in social science research during the completion of a master's thesis in their LIS program. While attending the conference Qualitative $\mathcal{E}$ Quantitative Methods in Libraries (QQML), the authors noticed that some of the presenters were recent LIS graduates from European LIS programs who were sharing the results of their master's thesis research. These observations led the authors to wonder about the impact of completing a master's thesis, either in LIS or in another master's degree program. Does this experience have a relationship to research productivity? The authors added two questions to address this question, one regarding the completion of a thesis in their LIS program and one in another master's degree program.

It is not necessary for a social science researcher to be an expert in statistics, but a basic understanding of statistics is necessary to undertake quantitative data analysis and helps researchers understand the ways in which a given research question may be formulated and studied. ${ }^{35}$ The authors' 2010 survey included questions about research methods courses, but what about other specific courses? Among the 10 questions on research confidence, the question on analyzing data scored the lowest. On a scale of 1 to 5 , with 1 being "Not at all confident" and 5 being "Very confident," out of 818 respondents the mean score was 3.26, which was the lowest score. On the expanded 38-item scale used to measure research confidence among IRDL Scholars, the questions on quantitative data analysis accounted for three of the five lowest average scores before the IRDL summer research workshop: "Knowing which statistical test(s) to run" (1.24); "Identifying which statistical package may assist you in analyzing your data" (1.36); "Knowing how to report the results of the statistical test(s) you have run" (1.70). ${ }^{36}$ To learn more about academic librarians' study of statistics, the authors added two questions, one asking whether the respondent had taken a course in statistics, and, if so, when: during their LIS master's program, their bachelor's program, another master's program, or another time? In a search of the literature for other studies that examine the effect of a master's thesis or a statistics course on research success, none were found.

Research mentoring and other institutional support (Q25). There is evidence that research mentoring may be an important success factor. Hoffman, Berg, and Koufogiannakis found that research mentoring is a well-established research success factor in other practitioner-research professions, but it has not been studied extensively in LIS. ${ }^{37} \mathrm{Re}-$ search mentoring has been studied extensively in fields such as professional psychology ${ }^{38}$ and academic medicine. ${ }^{39}$ In a well-designed and rigorous study of the academic advancement of women, minority, and generalist faculty in academic medicine, Palepu et al. examined mentoring and career development among junior faculty. ${ }^{40}$ Among 1,302 junior faculty respondents, 54 percent had received recent mentoring, defined as in the past three years. The faculty with mentors rated their research preparation and research skills higher than those without a recent mentor (3.8 vs. 2.9, $p<.0001$, on a six-point scale, $1=$ low and $6=$ high). The faculty with mentors allocated more time to research than did those without mentors $(28 \%$ vs. $15 \%, p<.0001)$. The faculty members with mentors were also more likely to have been awarded a research grant. ${ }^{41}$ There were no differences between the two groups regarding the number of publications in peer-reviewed journals (mean 12.5 vs. 13.5), but the authors speculated that the junior 
faculty may not have had time to publish their research yet. ${ }^{42}$ This finding is inconsistent with that of Levinson et al., who found that women medical school faculty who had mentors during their training averaged 13.1 publications compared with 10.3 articles for respondents without a mentor $(p<.05) .{ }^{43}$ Levinson et al. also found that women faculty who had mentors spent more time on research, an average of 25 percent of their time, compared with 21 percent for women faculty who had not had mentors. Palepu et al. found no differences between the groups of medical school faculty regarding their self-assessments of their teaching, administrative and clinical skills, suggesting that, for junior faculty, recent mentoring had the biggest impact on their research confidence. ${ }^{44}$

Recently, researchers have begun examining mentoring as a research success factor among academic librarian-researchers. Sassen and Wahl and Smigielski, Laning, and Daniels studied research success factors among librarians employed by the Association of Research Libraries member institutions. ${ }^{45}$ Sassen and Wahl found that 91 percent of the responding libraries offer informal mentoring and 52 percent offer formal mentoring. ${ }^{46}$ Smigielski, Laning, and Daniels found formal mentoring programs in 83 percent of libraries that grant tenure and 66.7 percent of libraries that do not. ${ }^{47}$ Mentoring was the fourth most prevalent institutional support mechanism for research among all responding libraries. ${ }^{48}$ Mentoring programs in academic libraries are often broader in scope than research mentoring, including learning about the institution and the profession, becoming professionally active through service, advising on dossier preparation, advancing in the organization, ${ }^{49}$ and developing leadership skills. ${ }^{50}$ Zhang, Deyoe, and Matveyeva conducted a study of the research mentoring program at Wichita State University Libraries and made recommendations for the development of an effective research mentoring program..$^{51}$ However, there have been few empirical studies on the effects of mentoring on research productivity in academic libraries. In a study of research productivity among the librarians of the Pennsylvania State University system, Fennewald found that, among interviewees, the most significant factor in research productivity was "the collegial support conveyed in formal and informal mentoring." 52 To gather more data on informal and formal research mentoring, the authors added these options to the list of institutional supports in the 2015 survey. They also added the response options of short-term pretenure research leave and incentives, such as merit pay or bonuses.

As both the 2010 and 2015 surveys were based upon the instrument developed by Powell, Baker, and Mika, the authors will comment on their findings in comparison to the authors' 2010 and 2015 findings, as appropriate. ${ }^{53}$ To make it clear when the data were gathered for all surveys, the year that the survey was conducted will be noted, instead of the year the results were published: Powell, Baker, and Mika conducted their survey in 2000, Kennedy and Brancolini conducted their survey in 2010, ${ }^{54}$ and the current survey was conducted in 2015. Although Powell, Baker, and Mika used a stratified random sample for their survey and the authors used purposive samples, the comparison of results over 15 years provides insight into how the research attitudes, involvement, and perceived capabilities of academic librarians may have changed and offer suggestions for how librarian-researchers might overcome research barriers and more effectively foster research success.

\section{Problem Statement}

This 2015 update survey aimed to capture a snapshot of the current attitudes and preparedness to conduct research to update what was learned five years prior, addressing the same questions as the 2010 survey: How do librarians currently participate in research? How confident do librarians feel about completing the various steps in the research process? How many and which kind of research design/methods trainings 
have librarians participated in, up to this point in their careers? How are librarians supported by their institutions in conducting research? The results of the 2010 survey helped to formulate the initial curriculum of a professional continuing education program about research design for practicing librarians. Functionally, in this 2015 survey, the authors wished to determine if any changes to the continuing education curriculum were warranted so it remains current and focused on skills as well as attitudes. In addition, the authors aimed to contribute to the ongoing discussion in the literature of success factors for librarians conducting research.

\section{Institute for Research Design in Librarianship}

Based on the results of the 2010 survey, the authors designed a continuing education program for academic librarians, the Institute for Research Design in Librarianship (IRDL). IRDL is funded through the Institute for Museum and Library Services Laura Bush 21st Century Librarian program grant (2013-2016 award \#RE-06-13-0060-13; 2016-2019 \#RE-40-16-0120-16), with matched funds from Loyola Marymount University, the home of IRDL. These funds permit the participants to attend IRDL at no personal cost (award includes travel, lodging, food, educational experience). The design of IRDL comes directly from the results of the 2010 survey, to focus on areas where librarians reported feeling the least confident or had the least experience. The authors of this article are the IRDL project codirectors.

Participants apply to the selective year-long program by submitting a research proposal, a statement about why they wish to attend IRDL, and a letter of support from their library's dean or director. An advisory board of practitioner-librarians, along with the project directors, craft a cohort that is diverse in several criteria: race (with emphasis given to self-reported ethnic and racial minorities); type of library (includes archives); geographical location; functional area of the library in which the applicant works; and area of research interest.

Once selected, the participants, called Scholars, prepare for the week-long workshop with a series of readings. During the workshop, the curricular focus is on hands-on experience with a variety of methods typically used in social science research. Ample time for one-on-one consultation is given throughout the workshop, so that the Scholars put their learning into immediate practice by revising their research protocols.

After the workshop is complete, the Scholars are supported for the academic year while they return to their home institutions and conduct their research projects. Measurements are taken throughout the workshop and following year to evaluate the effectiveness of the IRDL model. The model has been refined in all three years of the first grant (2013-2016 award), based on the results of the measurements, and will continue to be adjusted in the new three-year grant cycle. The 2015 survey about which this article is written was designed in part to discover if attitudes and needs of academic librarians have changed since 2010 and how those changes may be incorporated into the design of IRDL. For more information about IRDL, the reader may visit the project website at http://irdlonline.org.

\section{Methods}

\section{Survey Design}

To prepare for the 2010 survey, the authors carefully combed the literature, noting obstacles that librarians identified as barriers to conducting research. The authors built the survey around four areas of concern that would influence the curriculum design of the eventual IRDL: current research practice (reading, conducting research); confidence in completing the steps in a research project; any methods training completed; and identifying any institutional support for conducting research. Several of the questions 
were based upon those of Powell, Baker, and Mika's survey and Henry and Neville's, ${ }^{55}$ though some of their research questions diverged from those of the authors.

The flow of the 2015 survey followed that of the 2010 survey, with most of the questions phrased in the same way, in the same order. In 2015, the authors included an expanded confidence scale, additional response options for some questions, and four new questions about methods training. Unlike the 2010 survey, the 2015 survey had no forced responses. For the 2015 survey instrument and call for participation, see appendices $\mathrm{A}$ and $\mathrm{B}$.

\section{Current Research Practice}

The authors wanted to gain information about how actively engaged academic librarians are in their current research practice. Knowing whether academic librarians signify an interest in reading and/or conducting research, and how sincerely they are currently participating, would suggest to us if there was a potential audience for a continuing education opportunity related to research design. The 2010 study demonstrated to the authors the desire among academic librarians to continue their education for this, so the authors developed the Institute for Research Design in Librarianship. The authors' interest in repeating these questions is to note if there are any differences in the engagement in research practice in the current environment.

The survey began with a definition of "research," as noted earlier. The authors asked the respondents several questions about their research practice, starting with how the respondent stays current with the research literature. The authors asked if it is assumed that the respondent reads research literature as part of her job (Q1). The authors asked if the respondent is allowed time on the job for reading research literature $(\mathrm{Q} 2)$. The authors asked if the respondent regularly scans the tables of contents or abstracts of research-based articles and then followed by asking if he regularly reads the full content of research-based articles $(\mathrm{Q} 3, \mathrm{Q} 4)$. If the respondent does not regularly read research-based articles, the authors asked her to mark the possible reasons why, giving six options plus an "other" category that she could complete (Q5). If the respondent does regularly read research-based articles, the authors asked him to list the titles of two journals in which he regularly reads those articles (Q6).

The next three questions were about conducting research. At Q7, the authors asked if the respondent has conducted research since completing his library or information science (LIS) master's degree, giving an optional response for "N/A (Do not have an LIS master's degree)." If a respondent indicated that he has conducted research, the authors then asked if he has disseminated the results of the research to an external audience (Q8). If she responded that she has disseminated the results, the authors followed with a question about how they were disseminated; eight possible options were listed, plus an "other" category that she could complete (Q9).

\section{Confidence}

At this section, the authors introduce the largest change from the 2010 survey, a greatly expanded confidence scale. An exploratory factor analysis completed on the responses to the original 10-item scale suggested three factors were present, and so the authors expanded the questions about confidence within those three factors: planning, data, and reporting. ${ }^{56}$ Two of the items from the 10-item scale, "Performing a literature review" and "Identifying research partners, if needed," performed poorly in the factor analysis; "Performing a literature review" was reworded but "Identifying research partners, if needed" was not included in the further development of the scale. From the nine resulting items, the authors expanded within each of the three factors. Included in the scale, under the factor planning, the authors include Groups 1-3 (described 
below). Under the factor data are included Groups 4-5, and under the factor reporting are included Groups 6-8.

At Q10-17, the authors asked the respondents to rate their confidence in performing the discrete steps in a research project, on a scale of 1 to 5 , with 1 being "Not at all confident," 2 being "Slightly confident," 3 being "Moderately confident," 4 being "Confident," and 5 being "Very confident." The following thirty-eight items were measured, in eight groupings:

Group 1, the research question task (three items): (Q10) Turning your topic into a research question; Constructing a question that is reasonable in scope (not too narrow/ large, given your time and other assets such as money, support, research assistance); Determining if your research topic makes a contribution to the field, based on the relevant literature.

Group 2, research design (six items): (Q11) Designing a project to answer your question; Identifying other research studies similar to yours in order to examine the methods used; Exploring research designs that are appropriate for your question; Choosing a research design that is appropriate for your question; Selecting the methods and procedures for your question; Developing a timeline for the study.

Group 3, review of the literature (five items): (Q12) Writing a review of the literature appropriate for your research topic; Determining how your study can contribute to the existing literature; Identifying appropriate information sources in which to conduct your literature search; Using relevant keywords to discover literature about your research topic; Determining if a piece of literature is an appropriate source for your research question.

Group 4, data gathering (eleven items): (Q13) Gathering data; Determining which members of a population to include in your study; Determining how many members of a population to include in your study; Choosing appropriate qualitative data collection technique(s); Choosing appropriate quantitative data collection techniques; Choosing an appropriate data gathering procedure (what kind of data are you going to gather and how are you going to do it) (examples: in-depth interviews, focus groups, observation); Identifying appropriate sources of existing data; Knowing how to design a focus group; Knowing how to run a focus group; Knowing how to design a survey; Knowing how to administer a survey.

Group 5, data analysis (five items): (Q14) Analyzing data; Knowing how to organize the data you have gathered, or how to arrange existing data you may be using; Identifying which statistical package may assist you in analyzing your data; Knowing which statistical test(s) to run; Knowing how to code qualitative data to identify themes and sub-themes.

Group 6, writing results (four items): (Q15) Reporting results in written format; Knowing the components to construct a traditional social sciences journal article; Knowing how to apply a style guide (APA or MLA, for example); Knowing how to report the results of the statistical test(s) you may have run.

Group 7, verbally presenting results (two items): (Q16) Reporting results verbally; Knowing how to adapt your written research paper for oral presentation.

Group 8, disseminating results (two items): (Q17) Determining an appropriate format for disseminating results (poster/presentation/article); Identifying appropriate places to disseminate results (publication/conference).

\section{Methods Training}

The authors asked seven questions related to research training. The authors asked if the respondent believes that his LIS master's degree adequately prepared him to read and understand research-based literature (Q18) and then asked if the respondent believes 
that it adequately prepared him to conduct original research (Q19). At Q20, the authors asked if the respondent wrote a thesis in completing the LIS degree and, at Q21, if the respondent wrote a thesis in completing another master's degree. The authors asked if the respondent had taken at least one course in statistical analysis (Q22). If the respondent signified that she had, then a question followed about when she had taken the course(s) in statistical analysis, with response options: Part of my undergraduate work; part of my MLS coursework; part of my coursework for a non-MLS graduate degree; and other (with a text box for an explanation) (Q23). The authors asked the respondent to check any educational activities about research methods in which she has ever participated and to check all that applied (Q24). Questions 20-23 were newly added to the 2015 survey.

\section{Demographic Information}

The authors asked three questions to gather demographic information, to learn if research activities are supported at their current institutions, if their positions are tenure track, and if they have an advanced degree other than the LIS master's degree. The authors requested that the respondent check all the following research support options that his institution or library provided for librarians, giving eleven possibilities plus an option for "no research support for librarians" as well as "other" (with a text box for an explanation) (Q25). The authors asked if the respondent had worked in a position eligible for tenure and/or promotion, promotion only, or neither tenure nor promotion (Q26). Finally, the authors asked if the respondent has another graduate degree, in addition to her LIS degree, giving an optional response for "N/A (Do not have an LIS master's degree)" (Q27).

At Q28, the authors presented an optional text entry box for comments and feedback. On the last screen of the survey were featured citations to publications that informed some of the questions and Kennedy's contact information if the respondent wanted a report of the results of the survey.

Through field testing, the authors estimated that the survey would take fewer than ten minutes to complete. The survey protocol was reviewed by the Institutional Review Board at the authors' university.

\section{Survey Dissemination}

The survey was constructed using the software Qualtrics and was administered via the Internet. The authors solicited participation via listservs on which academic and/ or research librarians are members (see appendix B for the listservs to which the call was posted). There was one call for participation; no follow-up was pursued after the initial post. The survey was available for a month. There were no restrictions on who could choose to respond to the survey.

\section{Results}

The authors examined the survey responses regarding their four areas of concern: the current research practice of the respondent academic librarians; a self-evaluation of their confidence in performing the steps in the research process; a list of methods training courses in which they have participated; and demographic and institutional data related to support of library research.

Of the 793 respondents who began the survey, 669 of them completed it. For this analysis, incomplete surveys were not eliminated. The authors used all available data from each question to assist in comparing the responses from the Powell, Baker, and Mika 2000 survey, and the authors' own survey, conducted in 2010. The analysis here does not intend to generalize to the population of academic librarians since the sample 
of respondents was not systematically gathered. To be clear about the results, the authors report the total number of respondents (n) of each question.

\section{Reading and Conducting Research}

Eighty-four percent of the survey respondents $(n=767)$ say that it is assumed they will read research-based literature as part of their job as professional librarians, and 80 percent $(n=767)$ are allowed time on the job to do so; about 6 percent did not know if it was assumed they will read research-based literature as part of their job, and about 9 percent did not know if they were allowed time on the job to read. Seventy-eight percent $(n=767)$ scan tables of contents of journals that contain research-based literature, but only 58 percent regularly read the full content of those articles. The main reason stated for not regularly reading research-based literature is time; an overwhelming 199 (of $n$ $=469$ ) respondents noted this reason. Forty-four respondents noted that they did not enjoy reading research articles/no interest. Of those respondents who regularly read research-based articles, they identified College $\mathcal{E}$ Research Libraries as the main journal they read, followed by The Journal of Academic Librarianship (see appendix $C$ for the top fifteen journals noted in response to Q6, listing the titles of the journals in which the respondents regularly read research-based articles).

Seventy-seven percent of respondents $(n=721)$ have conducted research since completing the LIS degree, with 2 percent noting that they did not have an LIS master's degree. Of the 553 respondents who conducted research since completing the LIS degree, 83 percent (454) of them disseminated the results of their research. The main venues sought for dissemination were: presented at national conference; published in a refereed journal; presented at regional conference; and presented at home institution in an informal forum.

See table 1 for a comparison of responses from the 2010 and 2015 surveys, as well as the 2000 Powell, Baker, and Mika survey results, about reading and conducting research.

\section{Confidence}

The authors asked the respondents to rate their confidence in performing the discrete steps in a research project, on a scale of 1 to 5 , with 1 being "Not at all confident" and 5 being "Very confident." The 38 components were clustered together into eight groups of related tasks. In this section of results, the largest number of respondents in each grouping is noted. The largest number of respondents in the first group, the research question task (284; $\mathrm{n}=707)$, marked their confidence at 4 for "Turning your topic into a question that can be tested." In the next task, about research design, 277 respondents $(n=696)$ marked their confidence at 5 for "Identifying other research studies similar to yours in order to examine the methods used." In the next (third) task, about the review of literature, 402 respondents $(n=690)$ marked their confidence at 5 for "Using relevant keywords to discover literature about your research topic." A total of 240 respondents $(n=670)$ marked their confidence at 5 for the fourth task, "Gathering data." Fully 331 respondents $(n=667)$ marked their confidence at 1 at the fifth task, analyzing data, for "Knowing which statistical test(s) to run." In the sixth task, about the written reporting of results, 403 respondents $(n=664)$ marked their confidence at 5 for "Knowing how to apply a style guide (APA or MLA, for example)." In the seventh task, about the verbal reporting of results, $250(n=660)$ marked their confidence at 4 for "Reporting results verbally." In the eighth task 270 respondents $(n=660)$ marked their confidence at 4 for "Determining appropriate format for disseminating results (poster/presentation/article)."

See appendix D for a few examples of line graphs of each of the tasks and their responses on the confidence scale. The reader may notice in the graphs that most of 


\begin{tabular}{|c|c|c|c|c|c|c|c|c|}
\hline \multirow{7}{*}{ 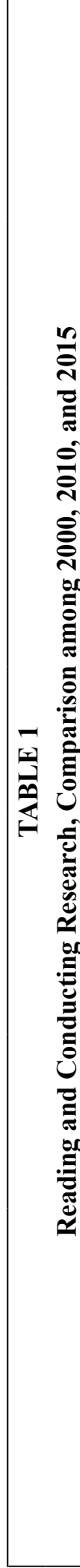 } & \multirow{2}{*}{ 串 } & 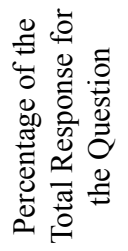 & 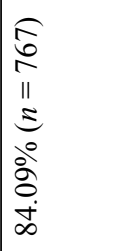 & 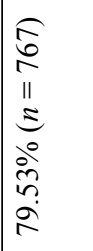 & 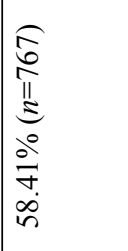 & 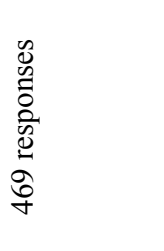 & 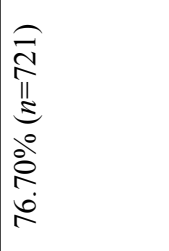 & 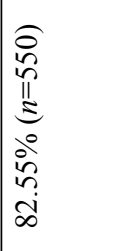 \\
\hline & & 芯 & 尔 & $\frac{0}{6}$ & $\underset{f}{\infty}$ & $\begin{array}{l}\stackrel{\partial}{\Xi} \\
\stackrel{\Xi}{\Xi}\end{array}$ & $\hat{n}$ & $\stackrel{+}{\sim}$ \\
\hline & 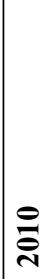 & 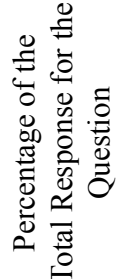 & 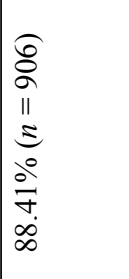 & 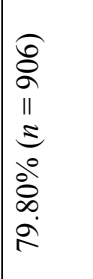 & 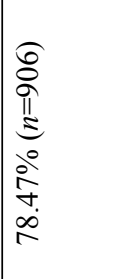 & $\begin{array}{l}0 \\
0 \\
0 \\
0 \\
0 \\
0 \\
0 \\
0 \\
n \\
n\end{array}$ & 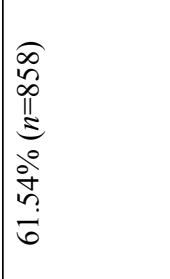 & 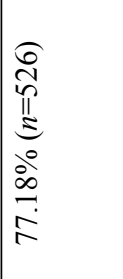 \\
\hline & & $\begin{array}{l}\vec{\Xi} \\
\dot{0}\end{array}$ & $\vec{\infty}$ & $\stackrel{N}{N}$ & $\bar{\nabla}$ & 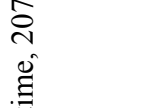 & $\begin{array}{l}\infty \\
\text { N }\end{array}$ & \&̊ \\
\hline & 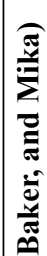 & 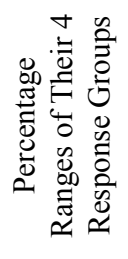 & 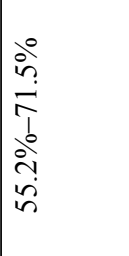 & $\begin{array}{l}\stackrel{0}{0} \\
\infty \\
0 \\
0 \\
\grave{0} \\
\text { ते } \\
\infty \\
\text { in }\end{array}$ & $\begin{array}{l}\partial^{0} \\
\hat{i} \\
0 \\
0 \\
\frac{0}{0} \\
\dot{n}\end{array}$ & $\begin{array}{l}0 \\
0 \\
0 \\
0 \\
0 \\
0 \\
0 \\
\text { ते } \\
\text { ते }\end{array}$ & 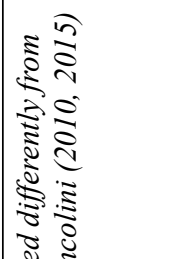 & 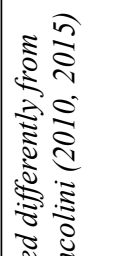 \\
\hline & $\begin{array}{l}\overline{0} \\
0 \\
0 \\
0 \\
0 \\
0 \\
0\end{array}$ & $\Rightarrow$ & $\bar{\sigma}$ & ?̊ & 离 & 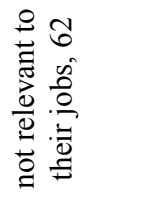 & 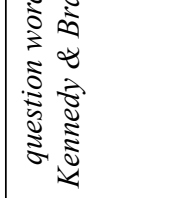 & 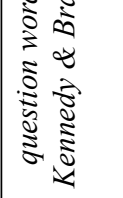 \\
\hline & & & 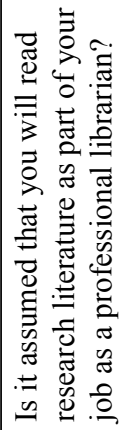 & 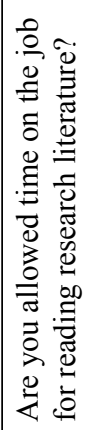 & 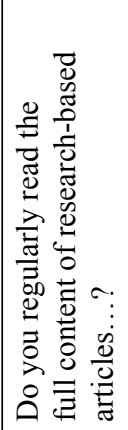 & 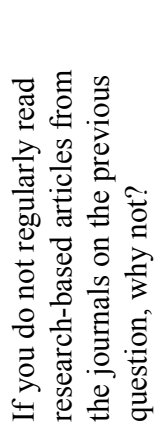 & 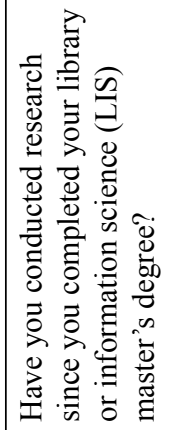 & 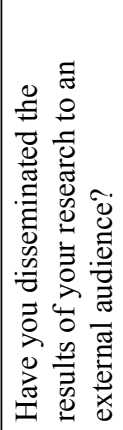 \\
\hline
\end{tabular}


the respondents highly rated their own confidence levels in completing the steps of a research project. The authors created a variable during analysis called Average Confidence and, for the thirty-eight steps on the 5-point scale (a possible 190 total points), an average of $3.41(n=647)$ was calculated.

As in 2010, the authors were interested to learn whether a respondent had conducted research since achieving the LIS degree was predicted by their confidence levels in performing the steps of a research project. To test this, the authors conducted a binary logistic regression in SPSS (Version 24), using the Enter method. The dependent variable was constructed from Q7, about whether the respondent has conducted research since completing his library or information science (LIS) master's degree, giving an optional response for "N/A (Do not have an LIS master's degree)." For this test, the authors removed the responses with the "N/A" answer since they were interested in the responses from those who had an LIS degree, which left behind only "yes" or "no" responses. The authors computed a new variable, Average Confidence, from Questions $10-17$, as the independent variable. The resulting model identified a significant correlation between conducting research and confidence at the 95 percent confidence level ( $n=694)$. Because the confidence scale ranged from 1 to 5 , any one-point change in an answer to any one-scale item (such as going from 3 to 4 ) represents a 3.3 percent increase in the odds of conducting research $(p<0.001)$. This suggests that confidence in performing the discrete steps in a research project continues to be useful as a predictor for whether a librarian conducts research.

Given that confidence was not a variable considered in the survey completed by Powell, Baker, and Mika and that the authors' own scale was altered greatly from the 2010 and 2015 versions, a comparative table related to confidence measures is not presented. The reader may find further information about the scale development from 2010 and 2015 in the article by Brancolini and Kennedy. ${ }^{57}$

\section{Methods Training}

The authors asked seven questions related to research methods training. Fifty-five percent $(n=659)$ believe that their LIS master's degrees adequately prepared them to read and understand research-based literature, but only 17 percent $(n=659)$ believe that their LIS master's degrees adequately prepared them to conduct original research. Twelve percent of the respondents $(n=659)$ completed a thesis as part of their LIS degree, and 27 percent $(n=659)$ wrote a thesis in completing another master's degree. About half of the respondents $(53 \%, n=659)$ have taken at least one course in statistical analysis, and of those taking the course, 46 percent $(n=468)$ took it as part of their undergraduate coursework. Of the educational activities about research methods in which they have ever participated, the top three are: self-education activities (examples: professional reading, online tutorial); formal master's degree LIS course(s) (examples: research methods, statistics); and continuing education program(s) (examples: courses, workshops, conference programs).

The authors expected that librarians would report having conducted research since achieving the LIS degree if they believed that their LIS degrees prepared them to conduct research. To test this, a chi-square test of independence was performed to examine the relation between conducting research (variable constructed from Q7, about whether the respondent has conducted research since completing his library or information science [LIS]) master's degree, with optional response for "N/A [Do not have an LIS master's degree]" removed) and belief that the LIS master's degree had prepared the respondent to conduct original research (variable constructed from Q19, about whether the respondent believes his/her LIS master's degree adequately prepared him/her to conduct original research, with the "N/A" answer removed from the set). The relation 
between these variables was not significant (chi-square with 1 degree of freedom $=1.65$, $p=0.199$ ). This finding is like the analysis of the 2010 data, in that whether librarians conduct research is not related to their belief that their LIS master's degree programs prepared them to do so. It is also consistent with the findings of Powell, Baker, and Mika. ${ }^{58}$

In the 2015 survey, the authors introduced two new questions, (1) asking if the respondent had written a thesis in completing the LIS degree, and (2) if the respondent had written a thesis in completing another graduate degree. The authors anticipated that librarians may report having conducted research since achieving the LIS degree if they already had experience with reporting of research by writing a thesis. To test this, a chi-square test of independence was performed to examine the relation between conducting research (variable constructed from Q7, about whether the respondent has conducted research since completing his library or information science [LIS] master's degree, with optional response for "N/A [Do not have an LIS master's degree]" removed) and writing a thesis in completing the LIS master's degree (variable constructed from Q20, about whether the respondent wrote a thesis in completing the LIS degree, with the "N/A" answer removed from the set). The relation between these variables was not significant (chi-square with 1 degree of freedom $=0.325, p=$ 0.568). The relationship between the variables of conducting research and writing a thesis in completing another graduate degree, however was significant (chi-square with 1 degree of freedom $=9.121, p=0.003$ ). Three-hundred eleven (of 462) that had conducted research since completing the LIS degree did not write a thesis in completing another graduate degree.

See table 2 for a comparison of responses from the 2000, 2010, and 2015 surveys, about methods training.

\section{Demographic Information}

\section{Institutional Support}

The authors added possible research success factors to the question on institutional support. In response to the question about research support options provided by their institutions or libraries, the two options noted most frequently are travel funds (partial reimbursement), and workshops or other forms of continuing education. Thirty-seven ( $5.62 \%$ of the respondents, $n=658$ ) responded that their institutions or libraries provided no research support for librarians. The authors expected to find a relationship between those librarians reporting that they had conducted research and those reporting some institutional support. To test this, a chi-square test of independence was performed to examine the relation between conducting research (variable constructed from Q7, about whether the respondent has conducted research since completing his library or information science [LIS] master's degree, with optional response for "N/A [Do not have an LIS master's degree]" removed) and institutional support for research (variable constructed from Q25, about any research support options that the institution provides for librarians). The relation between these variables was found to be significant (chi-square with 1 degree of freedom $=39.803, p<0.001$ ). Powell, Baker, and Mika also found a significant correlation between institutional support and librarians conducting research. ${ }^{59}$

The authors looked closer at two new items in the list of research support, formal and informal mentorship. They performed a chi-square test of independence to examine the relation between conducting research (variable constructed from Q7, about whether the respondent has conducted research since completing his library or information science [LIS] master's degree, with optional response for "N/A [Do not have an LIS master's degree]" removed) and formal mentorship (the item for "formal mentorship [experienced librarian researcher partners with novice researcher]" was checked at Q25). Of the 96 respondents (out of 646 total respondents, 15\%) who noted that their institution 


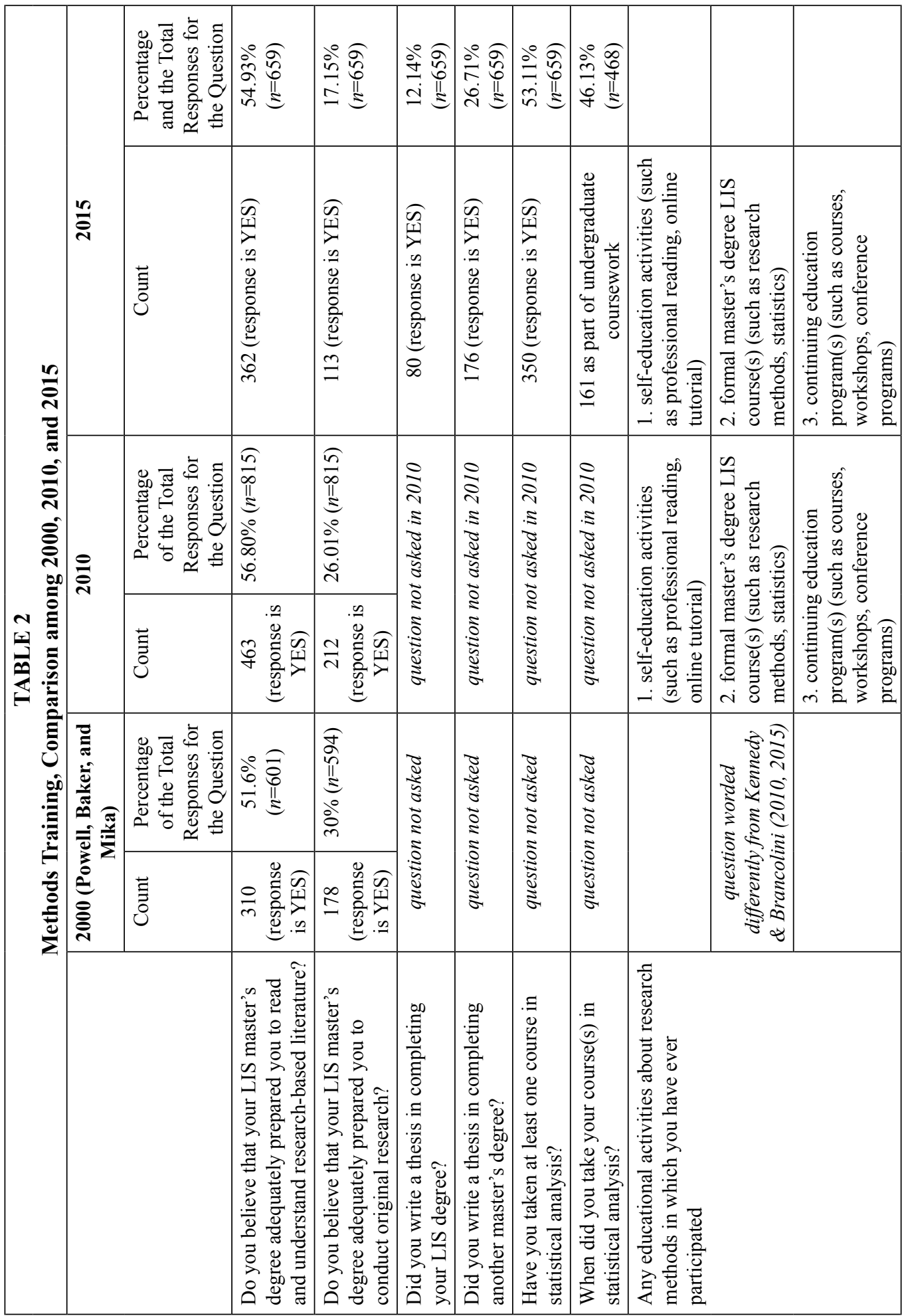


offered a formal mentorship, 88 (92\%) of those have conducted research. The relation between these variables was found to be significant (chi-square with 1 degree of freedom $=10.975, p<0.001$ ). They then examined informal mentorship and performed a similar chi-square test. Of the 259 (out of $646,40 \%$ ) who noted that their institution offered an informal mentorship (journal club discussions or article/proposal feedback sessions), $227(88 \%)$ of those have conducted research. The relation between the variables was found to be significant (chi-square with 1 degree of freedom $=19.677, p<0.001$ ).

Powell, Baker, and Mika asked three questions about support for conducting research, each with a yes/no response requested to the following: if respondents have time during working hours to do research; if they received internal or external support for research. One out of five $(20 \%)$ of their respondents noted that they received at least one of these three support mechanisms.

\section{Faculty Status and Additional Graduate Degrees}

The authors asked a question about faculty status and another question about additional graduate degrees. Fifty-five percent $(n=658)$ of the 2015 survey participants responded that they have worked in a position as a librarian that is eligible for promotion and/ or tenure. Forty-eight percent $(\mathrm{n}=658)$ have another MA, MS, or PhD, in addition to their LIS degree. Powell, Baker, and Mika did not include questions about promotion/ tenure or additional advanced degrees in their 2000 survey. The authors changed the wording of the questions about promotion and tenure in this recent survey so a comparison between the 2010 and 2015 is not represented in table 3.

\begin{tabular}{|c|c|c|c|c|c|c|}
\hline \multicolumn{7}{|c|}{$\begin{array}{c}\text { TABLE } 3 \\
\text { Demographic Information, Comparison among 2000, 2010, and } 2015\end{array}$} \\
\hline & \multicolumn{2}{|c|}{$\begin{array}{l}2000 \text { (Powell, Baker, } \\
\text { and Mika) }\end{array}$} & \multicolumn{2}{|c|}{2010} & \multicolumn{2}{|c|}{2015} \\
\hline & Count & $\begin{array}{l}\text { Percentage } \\
\text { of the } \\
\text { Total } \\
\text { Responses } \\
\text { for the } \\
\text { Question }\end{array}$ & Count & $\begin{array}{c}\text { Percentage } \\
\text { of the } \\
\text { Total } \\
\text { Responses } \\
\text { for the } \\
\text { Question }\end{array}$ & Count & $\begin{array}{l}\text { Percentage } \\
\text { and the } \\
\text { Total } \\
\text { Responses } \\
\text { for the } \\
\text { Question }\end{array}$ \\
\hline \multirow{2}{*}{$\begin{array}{l}\text { Research } \\
\text { support } \\
\text { options } \\
\text { that your } \\
\text { institution } \\
\text { or library } \\
\text { provides } \\
\text { for } \\
\text { librarians }\end{array}$} & \multirow{2}{*}{$\begin{array}{l}468 \text { have } \\
\text { time during } \\
\text { working } \\
\text { hours, } \\
\text { receive } \\
\text { internal or } \\
\text { external } \\
\text { support for } \\
\text { research }\end{array}$} & \multirow[t]{2}{*}{$\begin{array}{c}26.04 \% \\
(n=1,797)\end{array}$} & $\begin{array}{c}466 \text { (travel } \\
\text { funds, partial } \\
\text { reimbursement) }\end{array}$ & $\begin{array}{l}20.28 \% \\
(2,297)\end{array}$ & $\begin{array}{c}401 \text { (travel } \\
\text { funds, partial } \\
\text { reimbursement) }\end{array}$ & $\begin{array}{l}16.12 \% \\
(2,487)\end{array}$ \\
\hline & & & $\begin{array}{c}452 \\
\text { (workshops } \\
\text { or other forms } \\
\text { of continuing } \\
\text { education) }\end{array}$ & $\begin{array}{l}19.67 \% \\
(2,297)\end{array}$ & $\begin{array}{c}303 \\
\text { (workshops } \\
\text { or other forms } \\
\text { of continuing } \\
\text { education) }\end{array}$ & $\begin{array}{l}12.18 \% \\
(2,487)\end{array}$ \\
\hline $\begin{array}{l}\text { Do you } \\
\text { have } \\
\text { another } \\
\text { graduate } \\
\text { degree, in } \\
\text { addition to } \\
\text { your LIS } \\
\text { degree? }\end{array}$ & \multicolumn{2}{|c|}{ question not asked } & $\begin{array}{l}321 \text { (response } \\
\text { is YES) }\end{array}$ & $\begin{array}{l}39.68 \% \\
(n=809)\end{array}$ & $\begin{array}{l}317 \text { (response } \\
\text { is YES) }\end{array}$ & $\begin{array}{l}48.17 \% \\
(n=658)\end{array}$ \\
\hline
\end{tabular}


The relationship between the variables of conducting research since completing the master's LIS degree (constructed from Q7, about whether the respondent has conducted research since completing his library or information science [LIS] master's degree, with optional response for "N/A [Do not have an LIS master's degree]" removed) and eligibility for promotion and/or tenure was found to be significant, with 440 of the 509 respondents who noted that they had conducted research had also worked in a position as a librarian that is eligible for promotion and/or tenure (chi-square with 1 degree of freedom $=32.097, p<0.001$ ). Similarly, the relationship between conducting research and the completion of an additional graduate degree was found to be significant (chisquare with 1 degree of freedom $=17.451, p<0.001$ ).

\section{Discussion}

The 2010 survey was designed to gather data to scan the environment related to research attitudes and capabilities of academic and research librarians, as well as to assist in the development of a curriculum for a professional continuing education opportunity in research design. This 2015 survey was administered to determine if there were any significant changes that should be addressed in an update to the curriculum. Gathering a snapshot of current research-related attitudes and capabilities in the 2015 survey also allows the authors to begin to examine trends in this area over time. The large number of responses from the 2015 survey suggests that research is still a pressing issue for academic and research librarians. The results of the survey may assist in tailoring a revision to the curriculum in the following ways:

Current research practice. The authors learned from the survey that academic librarians are currently participating in reading research-based literature as part of their jobs. As in 2010, the respondents to the 2015 survey note time as the largest stated barrier to reading literature. During the initial three years of the Institute for Research Design in Librarianship (IRDL), the authors, who are the IRDL project codirectors, had multiple informal conversations with the Scholars about how to effectively manage time for the research process, especially as it relates to unanticipated delays due to changes to a research design midstream, or needing extended time to conduct analysis while learning new methodological techniques. In future IRDL workshops, the codirectors will demonstrate time-management techniques, like the Pomodoro Method and Gantt charts, to give the Scholars practical ideas about how to manage their research time. The codirectors have also devised a script for the Scholars to talk with their home institutions' managers about how to schedule time for reading and research.

The largest observed change from the results of the 2010 and 2015 surveys is related to the question, "Do you regularly read the full content of research-based articles...?" There was a 20 percent drop from 2010 to 2015 in the respondents signifying that they read the full content of research-based articles (78.47\% in $2010,58.41 \%$ in 2015). Since the sampling mechanism chosen by the authors was purposive, the authors do not intend to draw general conclusions about why this change may have occurred. As it relates to a possible curriculum revision, however, it may spur a conversation with the IRDL Scholars about the value gained by reading deeply, rather than simply skimming abstracts of research-based articles.

Confidence. The authors' use of a more granular confidence scale in the 2015 survey was helpful for the authors mainly in the future development and assessment of the curriculum for the Institute for Research Design in Librarianship. Having a more accurate measurement of confidence in the subcomponents of conducting a research project provides guidance for specific attention to those areas in the curriculum, especially as it relates to hands-on activities that are developed to reinforce preworkshop readings. 
Regarding the major components, compared to that of the 2010 survey, the authors do not observe any differences significant enough for comment.

Methods training. In 2015, compared to the responses of 2010, a lower percentage of respondents believe that their LIS master's degree prepared them to conduct original research (in 2010, 26\%; in 2015, 17\%).

The ratio of participation in educational activities about research methods remained the same in the five years between surveys, with self-education activities (examples: professional reading, online tutorial) being the first mentioned in both surveys, with formal master's degree LIS course(s) (examples: research methods, statistics) mentioned second, and continuing education program(s) (examples: courses, workshops, conference programs) mentioned third.

Demographic information. In the 2010 survey, $98(n=809)$ responded that their institution or library provided no research support options. This is a higher percentage $(12 \%)$ than was reported in 2015 (around 7\%), and it is encouraging to see this figure decreasing in the last five years, especially given the significant relationship between a librarian conducting research and their receiving support from their institution.

These survey results have implications for a broader application than the curricular adjustment for the IRDL. Related to current research practice, for example, a continuing concern is the time needed to complete any step in the research process. That issue, coupled with the finding that only about 60 percent of the 2015 survey respondents read the full content of research-based articles, may find a resolution via a journal club, in which the participants are prompted at a regularly scheduled interval to thoroughly read journal articles. Related to confidence, a finding from this study is that the respondents noted their lack of confidence in knowing which statistical test(s) to run. Participating in a workshop or course may mitigate that lack of knowledge, so that, when embarking on a research project, the librarian can do so confidently. The results of this survey noted that respondents participate in self-education activities to boost their knowledge about research methods. A list of such professional readings and courses could be constructed, so that others could participate in similar self-education activities, without the required research to discover ones that are appropriate. Related to demographic information, the authors were heartened to learn that institutions are providing more support for librarians conducting research. Librarians can advocate for increased support, and more diverse options for "support," so that librarians may participate more fully in research activities.

\section{Limitations of This Study and Future Research}

Now that the authors have completed two surveys of academic librarians about their research capabilities and interests and, in this article, compared it with similar work completed in 2000, the authors can begin to think about trends in this area. The next iteration of this survey, presumably in 2020, should employ a stricter sampling mechanism to provide an authoritative understanding of the research process for the respondents. The authors may consider replicating the survey, using a modification of the sampling design described in the work by Powell, Baker, and Mika. They surveyed librarians from all types of libraries, so they sampled members of four professional associations. The authors would likely limit sampling in a future survey to members of the association most closely aligned with academic librarians, the Association of College and Research Libraries. The authors may also want to look at other, more recent survey instruments that focus specifically on academic librarians, such as the one used by Hoffman, Berg, and Koufogiannakis to survey Canadian academic librarians. ${ }^{60}$

The 2015 survey asked about the availability of institutional support for research, but it did not specifically ask which of these supports had been used by respondents. The 
authors are especially interested in exploring more extensively the impact of mentorship, as high percentages of the respondents from institutions with mentoring programs reported research success, 92 percent for those with formal mentoring and 88 percent for those with informal mentoring. Future research might ask librarian-researchers specific questions about their mentoring experiences. The study published by Palepu et al. provides a possible model for further exploration of the relationship between research mentoring and research success, especially among novice researchers. ${ }^{61}$

\section{Summary}

In this article, the authors report findings from a 2015 survey of academic librarians about their attitudes, involvement, and perceived capabilities in the research process. An update to a survey the authors conducted five years prior, the findings from a purposive sample were similar. Regarding the authors' interest in discovering how librarians are currently participating in research, a notable finding from this survey was that only 58 percent of the respondents regularly read the full content of research articles; this is a significant decrease from the 2010 survey $(78.5 \%)$. This is disturbing, as research articles are primary sources of evidence for use in evidence-based practice and research ideas. As illustrated in the figures in appendix D, confidence in completing the steps in the research process appears very similar between the 2010 and 2015 surveys. Seventeen percent of the respondents believed that their LIS master's degree adequately prepared them to conduct original research, 9 percent fewer than in the 2010 survey (26.01\%). This is cause for concern, as LIS master's programs consider the relevance of their curricula and academic librarians search for ways to enhance and upgrade their research skills. The 2015 survey added some questions that reflect the latest research on research success factors for academic librarians: a more granular measure of research self-efficacy, academic preparation for research, and effective forms of institutional support for research, including formal and informal mentoring. The results confirm the importance of institutional support for librarian research success and provide new support for formal and informal research mentoring programs in academic libraries. 


\section{Appendix A. The Survey Instrument}

Welcome to the 2015 Academic Librarian Research Survey. Please complete this survey only one time.

For purposes of this study, we are defining research as: The process of arriving at dependable solutions to problems/questions/hypotheses through the planned and systematic collection, analysis, and interpretation of data: it may be applied or theoretical in nature and use quantitative or qualitative methods. (This definition does not include library research that is limited to activities such as compiling bibliographies and searching catalogs.)

Q1. Is it assumed that you will read research literature as part of your job as a professional librarian?
$\square \quad$ Yes
$\square \quad$ No
Don't know

Q2. Are you allowed time on the job for reading research literature?
口 Yes
$\square \quad$ No
․ Don't know

Q3. Do you regularly scan the tables of contents or abstracts of research-based articles in any journals like the ones listed here? (This is a sample list of journals that contain research-based articles)

College \& Research Libraries

Information Processing \& Management

Information Technology \& Libraries

Journal of Academic Librarianship

Journal of the American Society for Information Science E Technology

Journal of Library Administration

Library Resources \& Technical Services

$\begin{array}{ll}\square & \text { Yes } \\ \square & \text { No }\end{array}$

Q4. Do you regularly read the full content of research-based articles in any journals like the ones listed in the previous question?

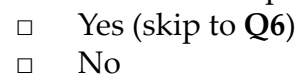

Q5. If you do not regularly read research-based articles from the journals on the previous question, why not? Check all that apply. If you choose Other, please tell us why you do not regularly read any of those journals.

$\square \quad$ Do not have enough expertise in research methods

$\square \quad$ Do not consider research-based articles to be relevant to my job

$\square \quad$ Prefer to read essays, opinion pieces, etc.

$\square \quad$ It is not expected that I will read research articles

$\square \quad$ I do not enjoy reading research articles / no interest

$\square \quad$ I do not have time

$\square \quad$ Other__ (text entry)

[Q6 displays if the answer to Q4 is Yes]

Q6. List the titles of two journals in which you regularly read research-based articles.

Journal 1

Journal 2 (text entry) (text entry) 
Q7. Have you conducted research since you completed your library or information science (LIS) master's degree?

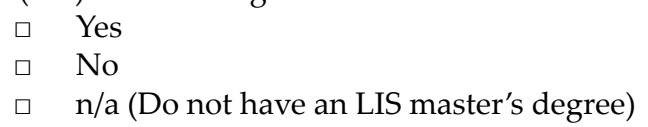

[Q8 displays if the answer to Q7 is Yes]

Q8. Have you disseminated the results of your research to an external audience?
$\square \quad$ Yes
№

[Q9 displays if the answer to Q8 is Yes]

Q9. How have you disseminated the results of your research? Check all that apply. If you choose Other, please tell us how you have disseminated the results of your research.

$\begin{array}{ll}\square & \text { Published a book (solo or co-author) } \\ \square & \text { Published in a book (contributed article) } \\ \square & \text { Published in a refereed journal (peer-reviewed, print or online) } \\ \square & \text { Published in a non-refereed journal (print or online) } \\ \square & \text { Published in conference proceedings } \\ \square & \text { Presented at a national conference } \\ \square & \text { Presented at a regional conference } \\ \square & \text { Presented at my home institution in an informal forum } \\ \square & \text { Other _ (text entry) }\end{array}$

The following eight sections ask you to rate your level of confidence in performing steps in a research project.

Q10. 1. On a scale of 1 to 5 , with 1 being "Not at all confident" and 5 being "Very confident," how would you rate your confidence in performing the following steps in a research project?

[Likert scale 1-5 presented for each entry]

- Turning your topic into a question that can be tested

- Constructing a question that is reasonable in scope (not too narrow/large, given your time and other assets such as money, support, research assistance).

- Determining if your research topic makes a contribution to the field, based on the relevant literature.

Q11. 2. On a scale of 1 to 5 , with 1 being "Not at all confident" and 5 being "Very confident," how would you rate your confidence in performing the following steps in a research project?

[Likert scale 1-5 presented for each entry]

- Designing a project to test your question

- Identifying other research studies similar to yours in order to examine the methods used.

- Exploring research designs that are appropriate for your question.

- Choosing a research design that is appropriate for your question.

- Selecting the methods and procedures for your question.

- Developing a timeline for the study.

Q12. 3. On a scale of 1 to 5 , with 1 being "Not at all confident" and 5 being "Very confident," how would you rate your confidence in performing the following steps in a research project?

[Likert scale 1-5 presented for each entry]

- Writing a review of the literature appropriate for your research topic.

- Determining how your study can contribute to the existing literature. 
- Identifying appropriate information sources in which to conduct your literature search.

- Using relevant keywords to discover literature about your research topic.

- Determining if a piece of literature is an appropriate source for your research question.

Q13. 4. On a scale of 1 to 5, with 1 being "Not at all confident" and 5 being "Very confident," how would you rate your confidence in performing the following steps in a research project?

[Likert scale 1-5 presented for each entry]

- Gathering data

- Determining which members of a population to include in your study.

- Determining how many members of a population to include in your study.

- Choosing appropriate qualitative data collection technique(s).

- Choosing appropriate quantitative data collection techniques.

- Choosing an appropriate data gathering procedure (what kind of data are you going to gather and how are you going to do it) (examples: in-depth interviews, focus groups, observation).

- Identifying appropriate sources of existing data.

- Knowing how to design a focus group.

- Knowing how to run a focus group.

- Knowing how to design a survey.

- Knowing how to administer a survey.

Q14. 5. On a scale of 1 to 5, with 1 being "Not at all confident" and 5 being "Very confident," how would you rate your confidence in performing the following steps in a research project?

[Likert scale 1-5 presented for each entry]

- Analyzing data

- Knowing how to organize the data you have gathered, or how to arrange existing data you may be using.

- Identifying which statistical package may assist you in analyzing your data.

- Knowing which statistical test(s) to run.

- Knowing how to code qualitative data to identify themes and sub-themes.

Q15. 6. On a scale of 1 to 5, with 1 being "Not at all confident" and 5 being "Very confident," how would you rate your confidence in performing the following steps in a research project?

[Likert scale 1-5 presented for each entry]

- Reporting results in written format

- Knowing the components to construct a traditional social sciences journal article.

- Knowing how to apply a style guide (APA or MLA, for example).

- Knowing how to report the results of the statistical test(s) you may have run.

Q16. 7. On a scale of 1 to 5, with 1 being "Not at all confident" and 5 being "Very confident," how would you rate your confidence in performing the following steps in a research project?

[Likert scale 1-5 presented for each entry]

- $\quad$ Reporting results verbally

- Knowing how to adapt your written research paper for oral presentation.

Q17. 8. On a scale of 1 to 5, with 1 being "Not at all confident" and 5 being "Very confident," how would you rate your confidence in performing the following steps in a research project?

[Likert scale 1-5 presented for each entry] 
- Determining an appropriate format for disseminating results (poster/presentation/article)

- Identifying appropriate places to disseminate results (publication/conference)

Q18. Do you believe that your LIS master's degree adequately prepared you to read and understand research-based literature?

$\square \quad$ Yes

$\square \quad \mathrm{No}$

n/a (Do not have an LIS master's degree)

Q19. Do you believe that your LIS master's degree adequately prepared you to conduct original research?

$\square \quad$ Yes

$\square \quad$ No

$\square \quad$ n/a (Do not have an LIS master's degree)

Q20. Did you write a thesis in completing your LIS degree?

$\square \quad$ Yes

$\square \quad \mathrm{No}$

$\square \quad$ n/a (Do not have an LIS master's degree)

Q21. Did you write a thesis in completing another master's degree?

$\square \quad$ Yes

$\square \quad$ No

$\square \quad$ n/a (Do not have an LIS master's degree)

Q22. Have you taken at least one course in statistical analysis?

$\square \quad$ Yes

$\square \quad \mathrm{No}$

[Q23 displays if the answer to Q22 is Yes]

Q23. When did you take your course(s) in statistical analysis? Please check all that apply. If you choose Other, please tell us when you took your course(s) in statistical analysis.

$\square \quad$ Part of my undergraduate coursework

Part of my MLS coursework

$\square \quad$ Part of my coursework for a non-MLS graduate degree

$\square \quad$ Other__ (text entry)

Q24. Please check any educational activities about research methods in which you have ever participated. Check all that apply. If you choose Other, please tell us about the educational activities about research methods in which you have participated.

Formal master's degree LIS course(s) (e.g., research methods, statistics)

$\square \quad$ Formal doctoral degree LIS course(s) (e.g., research methods, statistics)

Formal master's degree non-LIS course(s) (e.g., courses in other departments)

$\square \quad$ Formal doctoral degree non-LIS course(s) (e.g., courses in other departments)

$\square$ Continuing education program(s) (e.g., courses, workshops, conference programs)

$\square \quad$ Staff development program(s) provided by your organization

$\square \quad$ Self-education activities (e.g., professional reading, online tutorial)

․ None of these

$\square \quad$ Other (text entry)

Q25. Check all of the following research support options that your institution or library provides for librarians. Check all that apply.

$\square \quad$ Release time during the work week

$\square \quad$ Short-term pre-tenure research leave 
$\square \quad$ Sabbaticals for librarians

․ Travel funds (full reimbursement)

$\square \quad$ Travel funds (partial reimbursement)

$\square \quad$ Incentives (merit pay or bonuses)

$\square \quad$ Research grants

$\square \quad$ Formal mentorship (experienced librarian researcher partners with novice researcher)

口 Informal mentorship (journal club discussions or article/proposal feedback sessions)

$\square \quad$ Research design consultant or statistical consultant

․ Workshops or other forms of continuing education

$\square \quad$ No research support for librarians

$\square \quad$ Other (text entry)

Q26. Have you worked in a position as a librarian that is eligible for promotion and/ or tenure?
$\square \quad$ Tenure and promotion
$\square \quad$ Promotion only
$\square \quad$ Neither tenure nor promotion

Q27. Do you have another graduate degree, in addition to your LIS degree?
$\square \quad$ Yes
$\square \quad$ No
$\square \quad$ n/a (Do not have an LIS master's degree)

Q28. Do you have any comments or feedback for the researchers? 


\section{Appendix B. Wording of Call for Participation}

The following e-mail was posted to these listservs: Academic PR (Public relations and marketing in academic libraries); ARL-ASSESS (Association of Research Libraries Assessment group); ATLANTIS (Theological Librarians); AUTOCAT (Library Cataloging and Authorities Discussion Group); CALIBACA-L (California Academic \& Research Libraries Association); COLL-ASSESS (Collection Assessment); COLLIB-L (College Librarians List); DIG-PRES (Digital preservation); ILI-L (Information Literacy Instruction Discussion List); LIBREF-L (Discussion of Library Reference Issues); Metadatalibrarians; PRTalk (Public relations in libraries); ULS-L; West Arch (Western Archivists Listserv); VRA (Visual Resources Association); VRT-L (Video Round Table).

Subject line: 2015 Librarian Research survey call for participation

E-mail body: Help us learn about your research experience, capabilities, and attitudes! If you are an academic librarian, working in any library setting, we invite you to participate in a brief survey about your research skills and your institution's support for research. The survey is open through January 15, 2016.

The purpose of this survey is to update our 2010 study on the research activity of academic librarians. In this Web-based survey we will ask questions about:

- Your research practice,

- Your research training,

- How you would assess your own skills in completing discrete research tasks, and

- Institutional support for research.

The survey is expected to take about 10 minutes to complete. There will be no followup contact with you. Your participation in this study is completely voluntary and no risks are anticipated for you as a result of participating. This study has been reviewed by the Office of Research and Sponsored Projects at Loyola Marymount University. If you have any questions about your rights as a research participant in this study, please contact David Hardy, Ph.D. Chair, Institutional Review Board, 1 LMU Drive, Suite 3000, Loyola Marymount University, Los Angeles CA 90045-2659 (310) 258-5465, david.hardy@lmu.edu.

You may begin the study by going to this link: $<$ URL removed $>$ $<$ Author signature $>$ 


\section{Appendix C. Q6.}

List the titles of two journals in which you regularly read research-based articles.

\begin{tabular}{|l|c|}
\hline College \& Research Libraries & 232 \\
\hline The Journal of Academic Librarianship & 112 \\
\hline portal: Libraries and the Academy & 44 \\
\hline Communications in Information Literacy & 24 \\
\hline College \& Research Libraries News & 21 \\
\hline Journal of the Medical Library Association & 21 \\
\hline American Archivist & 20 \\
\hline Journal of Library Administration & 19 \\
\hline Evidence Based Library and Information Practice & 16 \\
\hline Journal of the Association for Information Science and Technology & 14 \\
\hline Reference \& User Services Quarterly & 13 \\
\hline Journal of Librarianship and Scholarly Communication & 11 \\
\hline Library Resources \& Technical Services & 11 \\
\hline Code4Lib Journal & 9 \\
\hline Library and Information Research & 9 \\
\hline
\end{tabular}




\section{Appendix D. The Confidence Levels of Some of the Research Tasks, Charted in a Line Graph}

\section{THE RESEARCH QUESTION}

- - Turning your topic into a research question

- Constructing a question that is reasonable in scope (not too narrow/large, given your time and other assets such as money, support, research assistance)

-Determining if your research topic makes a contribution to the field, based on the relevant literature

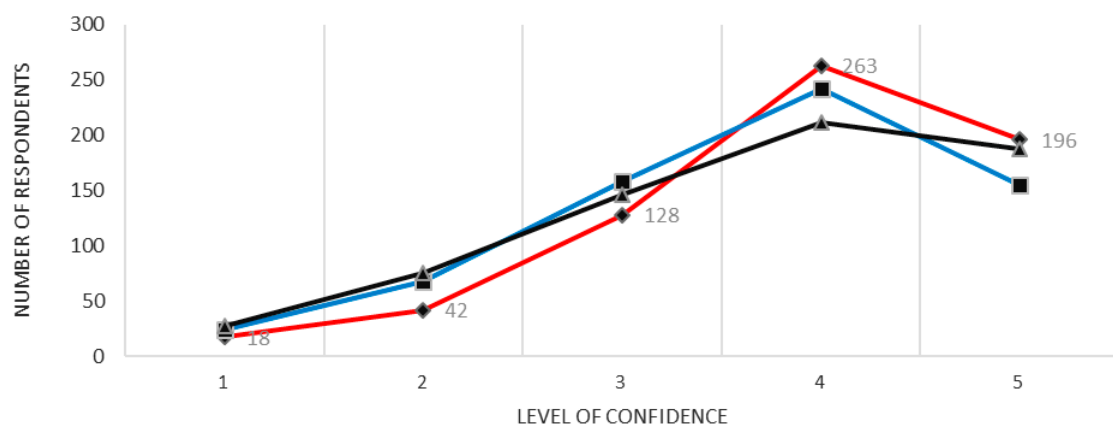

GATHERING DATA

$\square-$ Determining which members of a population to include in your study

$\triangle$ Determining how many members of a population to include in your study

$\rightarrow$ Choosing appropriate qualitative data collection technique(s)

* Choosing appropriate quantitative data collection techniques

- Choosing an appropriate data gathering procedure (what kind of data are you going to gather and how are you going to do it) (examples: in-depth interviews, focus groups, observation)

+ Identifying appropriate sources of existing data

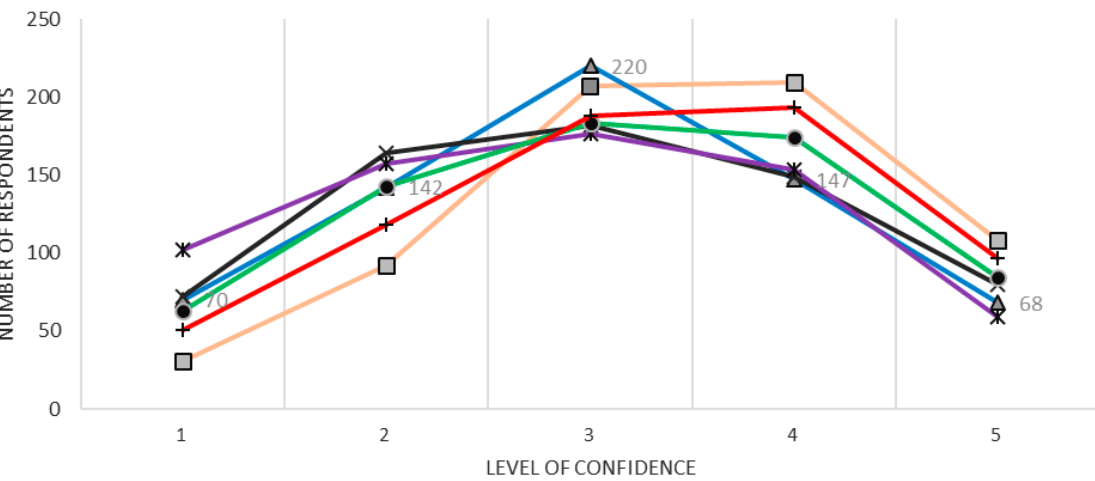




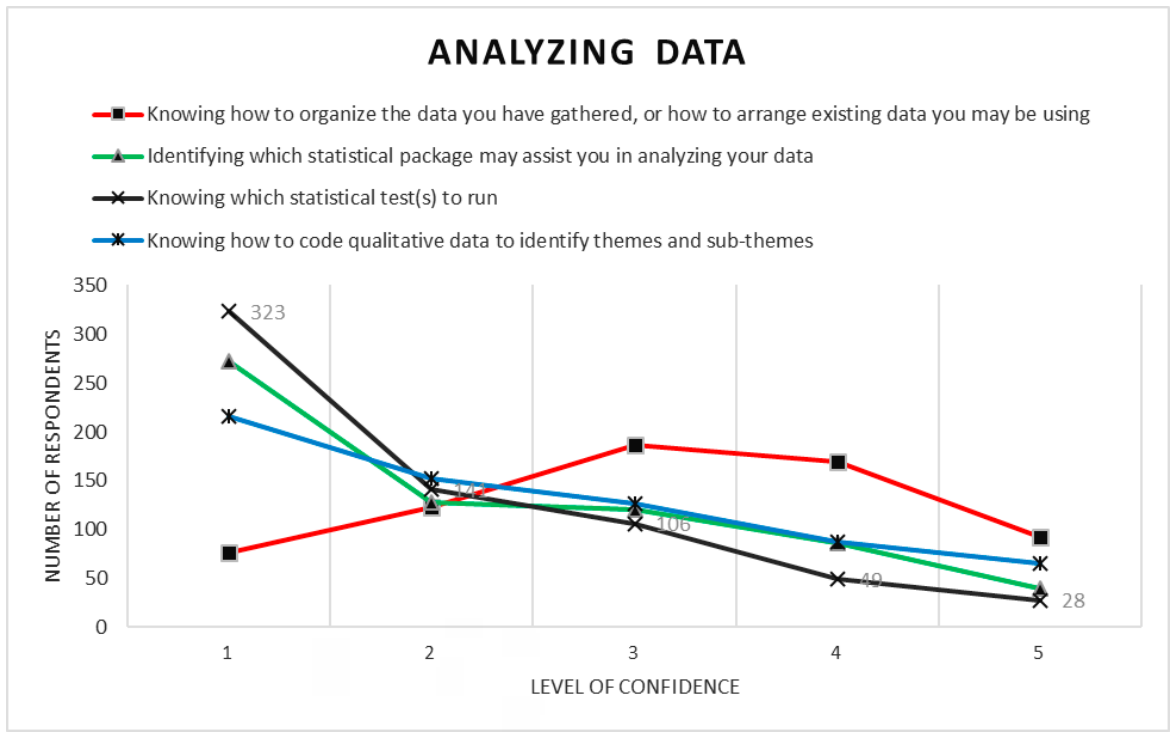

\section{Notes}

1. Ronald R. Powell, Lynda M. Baker, and Joseph J. Mika, “Library and Information Science Practitioners and Research," Library \& Information Science Research 24, no. 1 (2002): 49-72.

2. Deborah B. Henry and Tina M. Neville, "Research, Publication, and Service Patterns of Florida Academic Librarians," Journal of Academic Librarianship 30, no. 6 (2004): 435-51.

3. Marie R. Kennedy and Kristine R. Brancolini, "Academic Librarian Research: A Survey of Attitudes, Involvement, and Perceived Capabilities," College \& Research Libraries 73, no. 5 (2012): $431-48$.

4. Powell, Baker, and Mika, "Practitioners and Research."

5. Ibid., 54 .

6. Joseph Fennewald, "Research Productivity among Librarians: Factors Leading to Publications at Penn State," College \& Research Libraries 69 (2008): 104-16; Christopher V. Hollister, "An Exploratory Study on Post-Tenure Research Productivity among Academic Librarians," Journal of Academic Librarianship 42, no. 4 (2016): 368-81; Gay Helen Perkins and Amy J.W. Slowik, "The Value of Research in Academic Libraries," College E Research Libraries 74, no. 2 (2013): 143-58.

7. Virginia Wilson, "Formalized Curiosity: Reflecting on the Librarian Practitioner-Researcher," Evidence Based Library and Information Practice 8, no. 1 (2013): 111-17.

8. Rebecca Watson-Boone, "Academic Librarians as Practitioner-Researchers," Journal of Academic Librarianship 26, no. 2 (2000): 85-93.

9. Peter Jarvis, The Practitioner-Researcher: Developing Theory from Practice (San Francisco: Jossey-Bass, 1999).

10. Watson-Boone, "Academic Librarians as Practitioner-Researchers," 91.

11. Yu-Wei Chang, "Librarians' Contribution to Open Access Journal Publishing in Library and Information Science from the Perspective of Authorship," Journal of Academic Librarianship 41, no. 5 (2015): 660-68.

12. Yu-Wei Chang, "Characteristics of Articles Co-Authored by Researchers and Practitioners in Library and Information Science Journals," Journal of Academic Librarianship 42, no. 5 (2016): $535-41$.

13. Quinn Galbraith, Elizabeth Smart, Sara D. Smith, and Megan Reed, "Who Publishes in Top-Tier Library Science Journals? An Analysis by Faculty Status and Tenure," College \& Research Libraries 75, no. 5 (2014): 724-35; Lili Luo and Margaret McKinney, "JAL in the Past Decade: A Comprehensive Analysis of Academic Library Research," Journal of Academic Librarianship 41, no. 2 (2015): 123-29.

14. Galbraith et al., "Who Publishes in Top-Tier Library Science Journals?"

15. Ibid., 734 .

16. Denise Koufogiannakis and Ellen Crumley, "Research in Librarianship: Issues to Consider," Library Hi Tech 24, no. 3 (2006): 324-40; Jeannie P. Miller and Candace R. Benefiel, "Academic 
Librarians and the Pursuit of Tenure: The Support Group as a Strategy for Success," College $\mathcal{E}$ Research Libraries 59, no. 3 (1998): 260-65; Powell, Baker, and Mika, "Library and Information Science Practitioners and Research"; Zara Wilkinson, "Rock around the (Tenure) Clock: Research Strategies for New Academic Librarians," New Library World 114, no. 1/2 (2013): 54-66.

17. Lili Luo, "Fusing Research into Practice: The Role of Research Methods Education," Library E Information Science Research 33, no. 3 (2011): 191-201.

18. Powell, Baker, and Mika, "Library and Information Science Practitioners and Research."

19. Kennedy and Brancolini, "Academic Librarian Research."

20. Selinda Adelle Berg, Heidi L.M. Jacobs, and Dayna Cornwall, "Academic Librarians and Research: A Study of Canadian Library Administrator Perspectives," College E Research Libraries 74, no. 6 (2013): 560-72; Kristin Hoffmann, Selinda Adelle Berg, and Denise Koufogiannakis, "Understanding Factors That Encourage Research Productivity for Academic Librarians," Evidence Based Library and Information Practice (in press); Gay Helen Perkins and Amy J.W. Slowik, "The Value of Research in Academic Libraries," College \& Research Libraries 74, no. 2 (2013): 143-58; Ken N. Meadows, Selinda Adelle Berg, Kristin Hoffmann, Nazi Torabi, and Margaret Martin Gardiner, "A Needs-Driven and Responsive Approach to Supporting the Research Endeavors of Academic Librarians," Partnership: The Canadian Journal of Library and Information Practice and Research 8, no. 2 (2013): 1-32; Catherine Sassen and Diane Wahl, "Fostering Research and Publication in Academic Libraries," College \& Research Libraries 75, no. 4 (2014): 458-91; Elizabeth M. Smigielski, Melissa A. Laning, and Caroline M. Daniels, "Funding, Time and Mentoring: A Study of Research and Publication Support Practices of ARL Member Libraries," Journal of Library Administration 54, no. 4 (2014): 261-76.

21. Kristin Hoffmann, Selinda Adelle Berg, and Denise Koufogiannakis, "Examining Success: Identifying Factors That Contribute to Research Productivity across Librarianship and Other Disciplines," Library \& Information Research 38, no. 119 (2014): 13-28.

22. Ibid., 19.

23. Christopher V. Hollister, "An Exploratory Study on Post-Tenure Research Productivity among Academic Librarians," Journal of Academic Librarianship 42, no. 4 (2016): 368-81.

24. Ibid., 374.

25. Kathleen J. Bieschke, Rosean M. Bishop, and Victoria L. Garcia, "The Utility of the Research Self-Efficacy Scale," Journal of Career Assessment 4, no. 1 (1996): 59-75; Jeffrey H. Kahn, "Predicting the Scholarly Activity of Counseling Psychology Students: A Refinement and Extension," Journal of Counseling Psychology 48, no. 3 (2001): 344-54; Jeffrey H. Kahn and Norman A. Scott, "Predictors of Research Productivity and Science-Related Career Goals among Counseling Psychology Doctoral Students," Counseling Psychologist 25, no. 1 (1997): 38-67; Julia C. Phillips and Richard K. Russell, "Research Self-Efficacy, the Research Training Environment, and Research Productivity among Graduate Students in Counseling Psychology," Counseling Psychologist 22, no. 4 (1994): $628-41$.

26. Charles J. Gelso, Ellen C. Baumann, Harold T. Chui, and Alexandra E. Savela, “The Making of a Scientist-Psychotherapist: The Research Training Environment and the Psychotherapist," Psychotherapy 50, no. 2 (2013): 139-49.

27. Lori L. Bakken, Angela Byars-Winston, and Min-fen Wang, "Viewing Clinical Research Career Development through the Lens of Social Cognitive Career Theory," Advances in Health Sciences Education Theory and Practice 11, no. 1 (2006): 91-110.

28. Bieschke, Bishop, and Garcia, "The Utility of the Research Self-Efficacy Scale"; Michelle Forester, Jeffrey H. Kahn, and Matthew S. Hesson-McInnis, "Factor Structures of Three Measures of Research Self-Efficacy," Journal of Career Assessment 12, no. 1 (2004): 3-16.

29. Kennedy and Brancolini, "Academic Librarian Research."

30. Gary Holden, Kathleen Barker, Thomas Meenaghan, and Gary Rosenberg, "Research Self-Efficacy: A New Possibility for Educational Outcomes Assessment," Journal of Social Work Education 35, no. 3 (1999): 463-76.

31. Ibid., 466.

32. Kennedy and Brancolini, "Academic Librarian Research."

33. Sassen and Wahl, "Fostering Research and Publication in Academic Libraries," 458.

34. Gelso et al., "The Making of a Scientist-Psychotherapist," 142.

35. Charles J. Gelso, "On the Making of a Scientist-Practitioner: A Theory of Research Training in Professional Psychology," Training and Education in Professional Psychology S, no. 1 (2006): 3-16; Gelso et al., "The Making of a Scientist-Psychotherapist."

36. Kristine R. Brancolini and Marie R. Kennedy, "The Development and Use of a Research Self-efficacy Scale to Assess the Effectiveness of a Research Training Program for Academic Librarians," Library and Information Research 41, no. 124 (2017).

37. Hoffmann, Berg, and Koufogiannakis, "Examining Success."

38. Ronald T. Brown, Brian P. Daly, and Frederick T.L. Leong, "Mentoring in Research: A 
Developmental Approach," Professional Psychology: Research and Practice 40, no. 3 (2009): 306-13. 39. Wendy Levinson, Karen Kaufman, Clark Brinton, and Susan W. Tolle, "Mentors and Role Models for Women in Academic Medicine," Western Journal of Medicine 154, no. 4 (1991): 423-26; Anita Palepu, Robert H. Freidman, Rosalinda C. Barnett, Phyllis L. Carr, Arlene S. Ash, Laura Szalacha, and Mark A. Moskowitz, "Junior Faculty Members' Mentoring Relationships and Their Professional Development in U.S. Medical Schools," Academic Medicine 73, no. 3 (1998): 318-23.

40. Palepu et al., "Junior Faculty Members' Mentoring Relationships."

41. Ibid., 321.

42. Ibid., 322.

43. Levinson et al., "Mentors and Role Models for Women in Academic Medicine," 425.

44. Palepu et al., "Junior Faculty Members' Mentoring Relationships."

45. Sassen and Wahl, "Fostering Research and Publication in Academic Libraries"; Smigielski, Laning, and Daniels, "Funding, Time and Mentoring."

46. Sassen and Wahl, "Fostering Research and Publication in Academic Libraries."

47. Smigielski, Laning, and Daniels, "Funding, Time and Mentoring."

48. Ibid.

49. Allison Level and Michelle Mach, “Peer Mentoring: One Institution's Approach to Mentoring Academic Librarians," Library Management 26, no. 6/7 (2005): 301-10.

50. Kevin M. Ross, "Purposeful Mentoring in Academic Libraries," Journal of Library Administration 53, no. 7/8 (2013): 412-28.

51. Sha Li Zhang, Nancy Deyoe, and Susan J. Matveyeva, "From Scratch: Developing an Effective Mentoring Program," Chinese Librarianship: An International Electronic Journal 29 (2007): $1-16$.

52. Fennewald, "Research Productivity among Librarians," 112.

53. Powell, Baker, and Mika, "Library and Information Science Practitioners and Research."

54. Kennedy and Brancolini, "Academic Librarian Research."

55. Henry and Neville, "Research, Publication, and Service Patterns of Florida Academic Librarians."

56. Brancolini and Kennedy, "The Development and Use of a Research Self-Efficacy Scale." 57. Ibid. 65.

58. Powell, Baker, and Mika, "Library and Information Science Practitioners and Research,"

59. Ibid.

60. Hoffmann, Berg, and Koufogiannakis, “Understanding Factors That Encourage Research Productivity."

61. Palepu et al., "Junior Faculty Members' Mentoring Relationships." 